DOI: 10.2478/linpo-2014-0001

\author{
A R T I C L E S
}

\title{
The diaphonic aspect of phonotactics
}

\author{
Jerzy Bańczerowski \\ Institute of Linguistics Adam Mickiewicz University in Poznań
}

\begin{abstract}
Jerzy Bańczerowski. The diaphonic aspect of phonotactics. The Poznan Society for the Advancement of the Arts and Sciences. PL ISSN 0079-4740, ISBN 978-83-7654-384-0, pp. 13-28

The diaphonic aspect of phonotactics as a necessary counterpart of the isophonic aspect is being subjected to investigation. All assumptions and definitions are exemplified with Polish language material. Having recollected and relatively precisely explained phonological terms, indispensible for the subsequent inquiry, the distinction between diacrisis and diaphony is discussed, and several useful concepts such as the diaphonotacteme, diaphonic pair, diaphonic range, diaphonotactemic length etc. are introduced. Next some fundamental phonotactological terms are defined to which, among others, the following belong: diaphonic load, diacritic range, the diatactophoneme, diaphonic dispersion, diacritic dispersion, types of diaphony and diacrisis. Also some problems of diaphonic paradigm and diaphonic coding are considered. Finally, a phonotactological typology within the framework of comparative phnotactology of languages is postulated.
\end{abstract}

Keywords: phonotactics, comparative phonotactology

Isophony and diaphony - simple principles for the phonotactic coding of lingual signs.

\section{Introductory remarks}

This article is a continuation of the author's ongoing inquiry into theoretical phonotactology, already begun in Bańczerowski 2009 and 2013, and which mainly dealt with the isophonic aspect of phonotactics. Phonotactics, in addition to the isophonic aspect, also has a diaphonic aspect, which as a necessary counterpart of the former will be the object of the subsequent discussion. A diaphonic overview of phonotactics is thus indivisibly connected with an isophonic overview, since both complement each other. This specific complementarity has its origin in a fundamental principle which makes possible the effective handling of a great number of lingual signs. This principle also foresees the necessity of a certain kind of equilibrium between isophony and diaphony in the coding of these signs.

Lingual signs must be both sufficiently distinguished from each other as tokens of different types, and sufficiently equalized with each other as tokens of the same type, in order to guarantee the unambiguity of the message during communication. This goal is also served 
by the phonotactic coding specific for each and every ethnic language. The task of phonotactology is then, among other things, the recognition of the principles of this coding based on the sequentialization (linearization) of minimal lingual units, that is, sounds, as components of the phonic substance of signs.

Phonotactic coding is not able, however, to guarantee the phonic distinguishability of a given sign from all respective others. In order to do this for the universe of signs, phonotactics must work in tandem with the semantics of sentences and texts. This is especially noticeable in the case of homonymy, which involves complete isophony and which most probably operates in all languages.

\section{Some terminological reminders}

When exploring phonotactics in the light of isophony (Bańczerowski 2013) the author permitted himself once more to explain some terms, despite having done this many times before. The goal which guided him in doing so has always been the same, namely to give precise meanings to the linguistic terms used. Consequently, in order to lend clarity to the arguments below, the meanings of some terms will again be expounded on here. This should make their almost immediate recall possible and therefore enable the reader, if there is any, to follow the discussion without experiencing terminological doubts or speculation.

Phonotactology examines various aspects of phonotactic entities. Units which serve to code linearly structured objects may be sounds, phones, phonemes, or other phonal categories. The explicit distinguishing of these various kinds of objects is a necessary condition to effectively follow the present deliberations.

A sound is a linearly indivisible lingual object, that is, auditorily atomic from the point of view of a given language. It occurs in communicative space only once for a short time, whereupon it cannot be recovered from the past. Sounds are thus individual and concrete units of the linear ordering of lingual signs, and as actual entities they perpetually perish after being produced.

With the set of sounds and the relation of homophony at prior disposal, the latter reflecting the auditory indistinguishability of individual lingual objects, encompassing also sounds, it is possible to construct phones. Homophony as a relation of equivalence specifies the classification of the set of sounds into phones.

A phone is defined as a subset of all sounds homophonous with a given sound. Consequently the family of all phones is a classification of the set of sounds. In the examples which will be used here, capital letters will serve as symbols of the corresponding phones instead of phonetic transcription. The relation of homophonemicity, defined in turn on the family of phones, establishes a classification of this family into the family of phonemes.

The phoneme is defined as the maximal subset of phones related by free variation or complementary distribution and permissibly distant from each other phonetically (Batóg 1967: 97; Bańczerowski et al. 1982: 176). The sound then is an individual object, the phone is a set of homophonous sounds, and the phoneme is a set of homophonemic phones or, in other words, a set of sets of sounds.

In the present phonotactic investigation, an essential role will be played by linear structures associated with actual words, that is, vocabulons, treated here, similarly to sounds, as 
individual concrete lingual objects which are kinds of wholes in a mereological sense. From a purely physical, that is, articulatory and acoustic point of view, there are no explicit natural boundaries between sounds inside a word. To put it another way, no discontinuities between immediately contiguous sounds can be observed. Nonetheless, native linguators, on the basis of their lingual knowledge, have the strong impression while speaking and listening that they respectively pronounce and hear sequences of sounds. This impression arises as a result of the performance of auditory segmentation of objects which are articulatorily and acoustically continuous.

This virtual segmentation of vocabulons, which is an auditory creation by linguators, may be reflected in three ways with the help of three types of linear (sequential) structures, which are here called tactemes and which may be associated with vocabulons. There exist the following kinds of tactemes: (i) sonotactemes, (ii) phonotactemes, and (iii) phonemotactemes. They will be compared with each other below in order to demonstrate the fundamental differences between them.

A sonotacteme is the auditory product of a linguator. It takes on the shape of the linear structure of a corresponding vocabulon, made up of a sequence of sounds which follow one after another. In other words, a sonotacteme is made up of auditorily distinguished sounds in the vocabulon. Their linear order reflects their sequential occurrence in time. As a consequence the sonotacteme appears as the auditorily linear structure associated by the linguator with a vocabulon and, in fact, identified with it.

A phonotacteme is obtained from the transformation of a sonotacteme by replacing its constituent sounds with the phones to which those sounds belong. A phonotacteme reflects the linear structure of a vocabulon as a sequence of phones, which in contradistinction to the sounds making up the sonotacteme may be repeated in a phonotacteme. The phonotacteme of a given vocabulon may be called its phonetic or phonic representation. In the considerations that follow, discussion is restricted exclusively to vocabulonic phonotactemes.

A phonemotacteme, in turn, is obtained from a phonotacteme by replacing its constituent phones by the phonemes to which those phones belong. A phonemotacteme is thus a reflection of the linear structure of a vocabulon in terms of phonemes, which may be repeated in the phonemotacteme. The phonemotacteme of a given vocabulon may be called its phonological or phonemic representation.

Phonemotacteme, then, is a linear representation of a vocabulon encoded by means of phonemes. A phonotacteme is also a linear representation of a vocabulon, but encoded by means of phones. A sonotacteme in turn linearly represents a given vocabulon by means of its component sounds. Of these three types of tactemes, sonotactemes may be treated as lingual objects, and phonotactemes and phonemotactemes as linguistic constructs. All three of these types of tactemes were precisely defined earlier by Batóg (1967: 44, 115; 1978), using slightly different terminology. The present approach differs somewhat in its particulars.

Having the phonotacteme, it is possible to define the tactophoneme, which is also a basic object of phonotactics, reflecting the susceptibility of certain subsets of phones to the creation of phonotactemes. A tactophoneme is any set of phones from all of whose elements it is possible to create at least one phonotacteme representing the corresponding vocabulons. So in Polish, for example, the set of phones $\{A, K, T\}$ is a tactophoneme, since through sequentialization it codes the following phonotactemes, among others: $A K T$ ' act', $A T A K$ ' at- 
tack', $K A T$ 'executioner', $T A K$ 'yes', TAKT 'tact', $T K A$ 's/he weaves'. Apart from tactophonemes, other subsets of phones will also function as indispensible objects of phonotactics. These doubtless include the isotactophoneme and the diatactophoneme, which are certain subsets of phones within corresponding tactophonemes.

\section{Diacrisis and diaphony}

Two mutually dependent aspects of the heterophony of lingual signs are reflected in diacrisis and diaphony. With respect to its phonic substance, a lingual sign may differ from other signs completely or partly, in other words it may be completely or partially heterophonous with them. Both diacrisis and diaphony will be conceived of here as binary relations. The first will be considered in reference to phonotactemes, and the second in reference to their heterophonic component members.

The relation of diacrisis binds any two heterophonous phonotactemes without regard to whether they are completely or partially heterophonous. To put it another way, this relation is a set of heterophonous pairs of phonotactemes. Such pairs will be called diacritic pairs. Each of them is then an element of the relation of diacrisis. In accordance with the definition, the following pairs of phonotactemes, among others, belong to this relation in Polish:

$$
\begin{aligned}
& \text { (GLOS, KŁOS) 'voice', 'ear', } \\
& \text { (DOM, TAM) 'house', 'there', } \\
& \text { (BRAT, BLOK) 'brother', 'block', } \\
& \text { (GROT, GNAT) 'spearhead', 'bone', } \\
& (D A R, T O M) \text { 'gift', 'volume', } \\
& \text { (BRAT, TRAN) 'brother', 'cod-liver oil'. }
\end{aligned}
$$

The relation of diaphony binds every two maximal subphonotactemes on which the heterophony of at least two phonotactemes forming a diacritic pair is based. It is thus a set of heterophonous pairs of subphonotactemes, which will be called simply diaphonotactemes. In turn, a diaphonic pair will be any pair of diaphonotactemes which distinguishes at least one pair of phonotactemes forming a corresponding diacritic pair.

The diacritic pairs listed in (3.1) will now be used to give examples of the three terms introduced above, that is, the relation of diaphony, the diaphonotacteme and the diaphonic pair. The phonotactemes which form these diacritic pairs are heterophonous with respect to the presence in them of the following respective subphonotactemes:

$$
G-, K-; D O-, T A-;-R A T,-L O K ;-R O-,-N A-; D A R, T O M ; B-T, T-N \text {. }
$$

These subphonotactemes are then respectively in the relation of diaphony, by virtue of which they fulfill the function of diaphonotactemes. Moreover, they are also isodistributional and equal in phone number. They produce the following diaphonic pairs:

$$
(G-, K-),(D O-, T A-),(-R A T,-L O K),(-R O-,-N A-),(D A R, T O M),(B-T, T-N) .
$$

Diaphonotactemes can then be iso- or diadistributional as well as continuous or discontinuous. Below only those which are isodistributional and continuous will be dealt with. 
A diaphonotacteme can form diaphonic pairs with various diaphonotactemes. The diaphonic range of a given diaphonotacteme will be called the set of all diaphonic pairs in which that diaphonotacteme occurs. Thus, for example, the following diaphonic pairs belong to the diaphonic range of the diaphonotacteme $M-:(M-, W-),(M-, R-),(M-, D-)$, as can be ascertained on the basis of such diacritic pairs as:

$$
\begin{aligned}
& \text { (MY,WY) 'we', 'you (pl.)', } \\
& \text { (MATA, RATA) 'mat', 'installment', } \\
& \text { (MUR, DUR) 'wall', 'typhoid'. }
\end{aligned}
$$

The concept of the diaphonotactemic length turns out to be a useful concept for diaphonic typology. It will be here understood as the number of phone occurrences in the diaphonotacteme. Diaphonotactemic length does not always equal the number of phones which form it, because phones may be repeated within it. Thus, for example, the diacritic pair $(K A R A, K O E O)$ 'punishment', 'wheel' is based on the diaphonic pair $(-A R A,-O E O)$, both of whose diaphonotactemes are made up of two phones, of which one is repeated. The length of these diaphonotactemes is consequently 3. Each diaphonic pair the length of whose constituent diaphonotactemes equals 1 will be called a diaphonic minimal pair.

In the context of diaphonotactemic length, questions are raised about, among others:

(i) the sets of diaphonotactemes of particular lengths operating in a given language, that is, of lengths 1, 2, 3 etc.;

(ii) the number of diaphonotactemes of particular lengths.

It seems that the following empirical hypothesis is true, at least in a certain sense.

Hy 3.1 In every language there are more longer than shorter diaphonotactemes.

The interdependence between a diacritic and a diaphonic pair may be expressed as the relation of relative diaphony. It can be said that the diacritic pair $(X, Y)$ is diaphonic with regard to the diaphonic pair $(U, V)$ if and only if $U$ is a subphonotacteme in $X$ and $V$ is a subphonotacteme in $Y$.

Each diacritic pair which is made up of phonotactemes with different meanings and which is diaphonic with regard to a diaphonic minimal pair forms a diacritic minimal pair. The phones of which such a diaphonic pair is constituted are in phonological opposition. A possible hypothesis may be formulated as follows:

Hy 3.2 Every phone forms with some other phone a diaphonic minimal pair in a given language.

The length of diaphonotactemes that form such a pair is, of course, 1. To put it another way, each phone functions as a diaphonotacteme with a length of 1 . Some dependence between diaphonotactemes and phonotactemes may be grasped in terms of diaphonotactemic load as well as diaphonotactemic dispersion. 


\section{Diaphonic load}

Comparing a given phonotacteme with others, it is possible to distinguish within it those subphonotactemes that fulfill the function of diaphonotactemes, that is, those with regard to which it is heterophonous with these other phonotactemes. This can be considered on the example of the Polish phonotacteme TON 'tone', in which the following diaphonotactemes can be distinguished:

$$
\begin{array}{ll}
T \text { - (cf. } B O N \text { 'gift token'), } & T O-\text { (cf. } P A N \text { 'gentleman'), } \\
-O \text { - (cf. } T E N \text { 'this'), } & -O N \text { (cf. } T A M \text { 'there'), } \\
-N \text { (cf. } T O M \text { 'volume'), } & T O N \text { (cf. } D A R \text { 'gift'). }
\end{array}
$$

On the basis of the respective comparisons it can be ascertained that within the phonotacteme TON six continuous isodistributional diaphonotactemes operate. Thus, for example, this phonotacteme is heterophonous with the phonotacteme $B O N$ because of the diaphonic pair $(T-, B-)$, and with the phonotacteme $T A M$ because of the diaphonic pair $(-O N,-A M)$.

The set of all diaphonotactemes which may be distinguished in a given phonotacteme will be called its diaphonic load. The continuous diaphonotactemes $T-,-O-,-N, T O-,-O N$ and TON belong, among others, to the diaphonic load of phonotacteme TON. It can also be said that the phonotacteme $T O N$ is a carrier of the listed diaphonotactemes. As may thus be concluded, a given phonotacteme belongs to its diaphonic load.

The number of elements of a given phonotacteme's diaphonic load will be called its diaphonicity or diaphonic load power. Consequently, the diaphonicity of the phonotacteme $T O N$ is 6 . The diaphonicity of a given phonotacteme does not necessarily indicate the number of phonotactemes with which this phonotacteme is in the relation of diacrisis due to its diaphonotactemes.

The set of all phonotactemes which are in diacrisis with a given phonotacteme will be called its diacritic range. The elements of the diacritic range of the phonotacteme TON are the following phonotactemes:

$B O N$ 'gift token', JON 'ion', TEN 'this', TOM 'volume', TOK 'program', TOR 'track', TON 'depths', ŁAN 'field', PAN 'gentleman', FAN 'fan', TAM 'there', $T A K$ 'yes', TY‡ 'back', DAR 'gift', DUR 'typhoid',

and many others. As can easily be noted, the phonotacteme TON will in turn belong to the diacritic range of each phonotacteme which is an element of the diacritic range of TON. The phonotacteme $T O N$, however, will not belong to its own diacritic range.

The number of elements of the diacritic range of a given phonotacteme will be called its diacriticity or diacritic power. The diacriticity of a phonotacteme is, in principle, greater than its diaphonicity. The latter indicates only minimal diacriticity.

All four of the above defined terms - diaphonic load, diaphonicity, diacritic range and diacriticity - which refer to particular vocabulonic phonotactemes can be extended to the set of all vocabulonic phonotactemes of a given language. The total diaphonic load and total diacritic range are obtained by summing, respectively, the diaphonic loads and diacritic ranges of all phonotactemes of the language. The total diaphonic load should be, in principle, equal to the set of all diaphonotactemes of a given language, and the total diacritic range should be equal to the set of all phonotactemes of the language. 


\section{Types of diaphony and diacrisis}

A diaphonic pair has been defined as an object made up of two diaphonotactemes which distinguish phonotactemes of at least one diacritic pair so that its heterophony is assured. This heterophony can be obtained in two different ways, namely:

(i) by different phones which form diaphonotactemes, or

(ii) by a different linear ordering of the same phones.

The first of these ways of constructing diaphonic pairs is exhibited in the following diacritic pairs:

$$
\begin{aligned}
& \text { (BRON', DEOŃ) 'weapon', 'palm', } \\
& (D A R, T O R) \text { 'gift', 'track', } \\
& (K A R P, K A N T) \text { 'carp', 'edge', } \\
& (D A M A, D O B A) \text { 'lady', 'day (and night)'. }
\end{aligned}
$$

The second, permutational, way is exemplified by the following diacritic pairs:

$$
\begin{aligned}
& \text { (BARĆ, BRAĆ) 'beehive in a hole in a log or tree', 'to take', } \\
& \text { (KARTA, KRATA) 'card', 'bars', } \\
& \text { (WARTA, WATRA) 'guard', 'bonfire', } \\
& (R \dot{Z} E \dot{C}, \dot{Z} R E \dot{C}) \text { 'to neigh', 'to gobble', } \\
& \text { ( }(Z A, Z € A) \text { 'tear', 'bad (f.)', } \\
& \text { (TOWAR, WROTA) 'commodity', 'gate'. }
\end{aligned}
$$

Diaphonic type is the set of all diaphonic pairs with the same structure of diaphonotactemes. This structure may be determined on the basis of:

(i) phonic composition of the diaphonotacteme,

(ii) its length, or

(iii) metathesis, that is, the transposition of the same phones.

Among diaphonic pairs whose respective diaphonotactemes exhibit different phonic composition, the following types may be distinguished: $(X, Y),(X, \varnothing),(X Y, U V),(X Y, \varnothing Z)$, $(X Y, \varnothing \varnothing),(X Y U, V W Z)$. Instead of letter symbols, the following digital symbols may be used to represent these respective types as follows: $(1,1),(1,0),(2,2),(2,01),(2,00)$, $(3,3)$. The digital symbolization also expresses the length of the diaphonotacteme. Thus it will be said that the diaphonic pair (TO-, DA-) belongs to the types $\left(X Y-, U V_{-}\right)$and $(2,2)$. Among diaphonic pairs whose diaphonotactemes are based on metathesis, the pairs $(R \dot{Z}$-, $\dot{Z} R-),(\lfloor Z-, Z L-),(-A R-,-R A-)$ and (-RT-, -TR-) belong to the type (-XY-, $-Y X-)$.

Each particular type of diaphony will specify the corresponding type of diacrisis. To put it another way, the type of the first kind will determine the type of the second kind. The diacrisis type will be defined as the set of all diacritic pairs of which each is based on a diaphonic pair which belongs to the same type of diaphony.

Analogically to types of diaphony, the corresponding types of diacrisis can be distinguished and indicated by the same symbols. The diacritic pairs listed earlier in (5.1) (BRON, $\left.D E O N^{\prime}\right)$, and $(D A R, T O R)$ thus belong to the diacritic type $(X Y-, U V-)$ as well as to type 
$(2,2)$. The pairs listed in (5.2) ( $Ł Z A, Z € A)$ and (WARTA, WATRA) belong to the types (XY-, $Y X-)$ and $(-X Y-,-Y X-)$, respectively.

A particular type of diaphony is $(X, Y)$, that is $(1,1)$, which specifies the type of diacrisis whose elements are minimal pairs. Phones that form diaphonic pairs of this type may be bound by phonological opposition. Some pairs of phones, however, do not form diaphonic pairs, whence the phonological ranges of particular phones will differ. By the phonological range of a phone $X$ we mean the set of all phones with which $X$ enters into phonological opposition. The number of elements of this range will be called the phonological strength of phone $X$. Phones then may be compared both with respect to their phonological range and to their phonological strength. Pairs of phones which do not form diaphonic pairs are diaphonically empty, and as a result they do not belong to phonological opposition. The following hypothesis seems to hold true:

Hy 5.1 Every phone forms a diaphonic pair with at least one other phone.

This would simply mean that every phone of a given language enters into phonological opposition with at least one other phone.

The typologicization of diaphony and diacrisis can also be indicated through the use of articulatory or acoustic categories of the phones that form diaphonotactemes. For this purpose such symbols as $C$ (consonant), $V$ (vowel), $O$ (stop), $S$ (fricative), $N$ (nasal) or $L$ (liquid) may be applied. Consequently, the diacritic pair (DRUGA, SMUGA) 'second adj. f.', 'trail' can be assigned to the categorial diacrisis types (CC-, $C C$-) and ( $O L-, S N-)$, which clearly indicate the categorial composition of consonant clusters that function as diaphonotactemes. Types of diaphony, like types of diacrisis, thus belong to the domain of phonotactological typology.

\section{The diatactophoneme}

Diaphonotactemes have been defined as subphonotactemes, or the components of phonotactemes. As fragments of these last, they are then also linear structures made up of sequentially ordered phones. In particular cases they may consist of one phone. A diatactophoneme will be defined as any subset of phones from whose elements and only from them it is possible to create at least one diaphonotacteme in a given language.

Having such diacritic pairs as: (GŁOWA, TRAWA) 'head', 'grass', (KANT, KARK) 'edge', 'nape of the neck' it can be ascertained that they are based on the respective diaphonic pairs (GŁO-, TRA-) and (-NT, $-R K)$. The diaphonotactemes occurring in these diaphonic pairs are made up of the following respective subsets of phones: $\{G, E, O\},\{A, R, T\},\{N, T\}$ and $\{K, R\}$. In accordance with the definition, these subsets are diatactophonemes.

The diatactophoneme, as a phonotactic object, lends itself to characterization with regard to such parameters as:

(i) phonicity,

(ii) diaphonotactemic range, and

(iii) diaphonotactemicity.

The number of phones that form a given diatactophoneme will be called its phonic power or simply its phonicity. However the set of all diaphonotactemes which arise as a result of 
the sequentialization of diatactophoneme $\mathfrak{X}$, that is, which are coded by $\mathfrak{X}$, will be called its diaphonotactemic range, and the number of elements which belong to this range will be determined as the diaphonotactemicity of the diatactophoneme $\mathfrak{X}$. It can also be said that a given diaphonotacteme specifies the respective diatactophoneme.

Characterizing the Polish diatactophoneme $\{A, R, T)$ relative to the above-mentioned parameters, it can be stated that its phonicity is equal to 3 , since it is made up of three phones. The following eight diaphonotactemes belong to its diaphonotactemic range: $A R T$-, ATR-, RAT-, TAR-, TRA-, TART-, TATR-, TATAR-. This conclusion is reached on the basis of such diacritic pairs as:

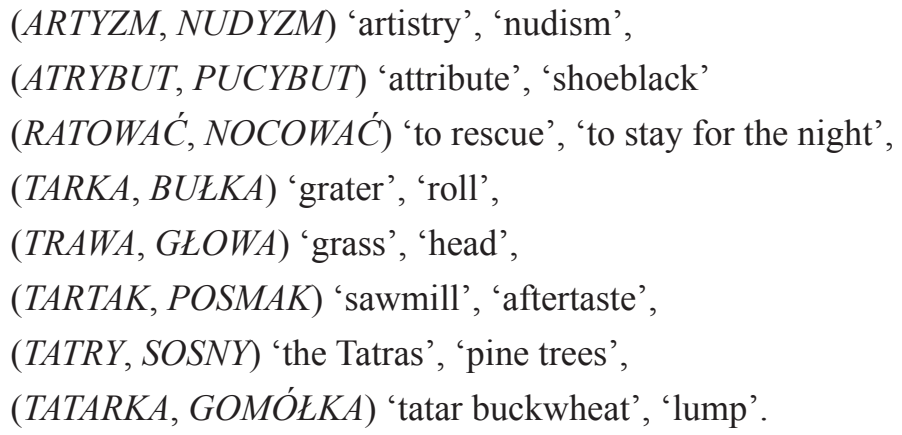

The diaphonotactemicity of the diatactophoneme $\{A, R, T\}$ cannot be less than 8 .

Diatactophonemes may be made up of one or more phones, that is, they may be mono-, bi-, triphonic and so on. Considering the issue theoretically and without taking into account the repetitions of phones, from a monophonic diatactophoneme it is possible to form only one diaphonotacteme, from a biphonic diatactophoneme 2, from a triphonic diatactophoneme 6, and from a tetraphonic diatactophoneme 24. Of course, no language makes use of all of its theoretical possibilities. It should also be remembered that from the same diatactophoneme it is possible to create diaphonotactemes which are

(i) continuous, or

(ii) discontinuous, and this in turn increases the number of possibilities.

Comparing the diatactophonemes of any language with respect to the parameters of phonicity and diaphonotactemicity, it will be possible to establish which diatactophonemes are

(i) equiphonic, that is, they are made up of the same number of phones, and which are

(ii) equidiaphonotactemic, that is, they code the same number of diaphonotactemes.

The relation of equiphonicity thus specifies the classification of diatactophonemes into those that are mono-, bi- and triphonic etc. The relation of equidiaphonotactemicity, in turn, specifies the classification of the diatactophonemes so that each element of this classification is a set of diatactophonemes coding the same number of diaphonotactemes. With regard to these two parameters, it is possible to establish the respective hierarchies or rankings of the diatactophonemes of a given language.

Each diatactophoneme may be associated with its categorial characteristics, that is, the set of articulatory categories to which the phones of this diatactophoneme belong. Thus, for 
example, the diatactophoneme $\{A, R, T\}$ possesses the categorial characteristics $\{V, L, O\}$ where $V$ refers to a vowel, $L$ to a liquid and $O$ to a stop (occlusive).

The concept of diaphonotactemic range can also be considered from a global standpoint, that is, it is possible to extend it to all of the diatactophonemes of a given language. In connection with this the following questions immediately arise:

Qs 1 Which subsets of phones of a given language form diatactophonemes within it?

Qs 2 How many diatactophonemes are there in the language?

Qs 3 How many diatactophonemes exhibiting a particular phonicity (that is, mono-, bi-, triphonic, etc.) are there in the language?

Qs 4 How many diaphonotactemes are there specified by diatactophonemes of a particular phonicity?

Obviously, the answers to these questions would require tedious calculations.

\section{Diaphonic dispersion}

Phonotactic dispersion should also be counted among those terms that are useful for phonotactology. Defining it as generally as possible, it could be said that it refers to the occurrence of lesser phonotactic objects within greater objects. It is possible to distinguish, among others, two kinds of such dispersion, which are:

(i) isophonic dispersion, and

(ii) diaphonic dispersion.

The first of these has already received some attention in Bańczerowski 2013. As for the second, the four following sub-kinds may be distinguished:

(i) diatactophonemic dispersion of phones,

(ii) diacritic dispersion of diaphonic pairs,

(iii) diaphonic dispersion of diaphonotactemes,

(iv) diacritic dispersion of diaphonotactemes.

These sub-types of dispersion will be defined, and then examples will be given.

The set of all the diatactophonemes to which a given phone belongs will be referred to as its diatactophonemic dispersion. The number of elements of this set will be defined as the power of diatactophonemic dispersion of this phone. The dispersion, like its power, may be established in terms of mono-, bi-, tri-phonic, etc. diatactophonemes. The following diatactophonemes, among others, will belong to the diatactophonemic dispersion of the Polish phone $M:\{M\},\{M, O\},\{M, A\}$. This is attested by such diacritic pairs as $(M Y, W Y)$ 'we', 'you', (MOWA, ŁAWA) 'speech', 'bench', (MATA, NUTA) 'mat', 'note'.

The set of all diacritic pairs which are based on a given diaphonic pair will be called its diacritic dispersion. The number of elements in this set will be called the power of diacritic dispersion of this diaphonic pair. The following diacritic pairs, among others, belong to the diacritic dispersion of the diaphonic pair (KA-, RO-): (KASA, ROSA) 'cash desk', 'dew', (KALKA, ROLKA) 'carbon paper', 'roll', (KAPA, ROPA) 'bedspread', 'pus'. If then a diacritic pair $(X, Y)$ belongs to the dispersion of the diaphonic pair $(U, V)$, then $U$ is a member of $X$ and $V$ is a member of $Y$. The diacritic dispersion of a given diaphonic pair thus reflects the spread of that pair in the diacritic pairs of a given language. 
The set of all diaphonic pairs whose members is a given diaphonotacteme will be called its diaphonic dispersion. This kind of dispersion reflects the spread of a given diaphonotacteme as a member of different diaphonic pairs. A given diaphonotacteme contrasts with various other diaphonotactemes, forming diaphonic pairs, as can be illustrated by, among others, the following diacritic pairs: (MAK, TAK), (MATA, RATA), (MUR, DUR), (MODA, $R A D A),(M O C, K A C)$, (MOTOR, ZATOR). On the basis of the first three pairs it can be stated that the diaphonic pairs $(M-, T-),,(M-, R-)$ and $(M-, D-)$ belong to the diaphonic dispersion of the diaphonotacteme $M$-, and on the basis of the last three pairs it can be stated that the diaphonic pairs $\left(M O^{-}, R A^{-}\right),\left(M O^{-}, K A^{-}\right)$and $\left(M O_{-}^{-}, Z A^{-}\right)$belong to the diaphonic dispersion of the diaphonotacteme $M O$-.

The diacritic dispersion of a diaphonotacteme $X$ will be defined as the set of all phonotactemes in which $X$ occurs and which form diacritic pairs with other phonotactemes with respect to $X$. The number of elements of this set will be called the power of diacritic dispersion of the diaphonotacteme $X$. This kind of dispersion reflects the spread of diaphonotactemes in phonotactemes which are diaphonic with other corresponding phonotactemes only with regard to those diaphonotactemes. It should be kept in mind that the identification of the subphonotacteme $X$ as a diaphonotacteme, which with a subphonotacteme $Y$ forms a diaphonic pair $(X, Y)$, can only be made on the basis of those pairs of phonotactemes which form diacritic pairs relative to $(X, Y)$. So, for example, the fact that the subphonotacteme $K A$ - functions as a diaphonotacteme forming with $R O$ - the diaphonic pair $(K A-, R O-)$ can be recognized on the basis of diacritic pairs such as (KASA, ROSA), (KALKA, ROLKA). The subphonotacteme $K A$ occurs also in the phonotacteme $K A R K$, which does not, however, form a diacritic pair with $* R O R K$, since such a phonotacteme does not exist in Polish. Thus the phonotacteme $K A R K$ is not sufficient to ascertain whether $K A$ - is a diaphonotacteme which forms a diaphonic pair with $R O$-.

Summing up, it should be emphasized that the identification of a given subphonotacteme as a diaphonotacteme which forms a given diaphonic pair with another subphonotacteme can occur only with regard to a certain set of respective diacritic pairs. Thus the performance of the function of a diaphonotacteme by a given subphonotacteme should always be relativized to a certain set of diacritic pairs. The intriguing question arises, however, of whether diaphonically empty (kenotic) subphonotactemes exist.

\section{The diaphonic paradigmatization of diacritic pairs}

Every diaphonotacteme, as a phonotactic unit of the diaphonic coding of phonotactemes, is in the relation of diaphony with another diaphonotacteme, so that at least one diacritic pair is based on that relation. A number of diacritic pairs may however exhibit one and the same diaphonic pair. This repeatability of diaphonic pairs in various diacritic pairs binds these second in one set, since they are diaphonically similar to each other, or to put it another way, they are homodiaphonic. Such an understanding will necessarily lead to the idea of a diaphonic paradigm, which is one of the fundamental objects of phonotactics, and which results from the bringing together of homodiaphonic diacritic pairs into the corresponding set.

The diaphonic paradigm specified by the diaphonic pair $(X, Y)$ will be called the set of all diacritic pairs distinguished exclusively by this pair, whose members $X$ and $Y$ are 
isodistributional in the phonotactemes that form these diacritic pairs. The diaphonic pairs $(M-, W-),(K A-, M O-)$ and $(-A R-,-R A-)$ will be used to illustrate the diaphonic paradigm so defined. They specify, respectively, the following paradigms:

$$
\begin{aligned}
& \text { (MATA, WATA) 'mat', 'cotton wool', } \\
& \text { (MODA, WODA) 'fashion', 'water', } \\
& \text { (MANNA, WANNA) 'manna', 'bathtub', } \\
& \text { (MAT, WAT) 'checkmate', 'watt', } \\
& \text { (MY,WY) 'we', 'you (pl.)', } \\
& \text { (MARA, WARA) 'dream', 'hands off', } \\
& \text { (MĄŻ, WAZŻ) 'husband', 'snake', } \\
& \text { (MYĆ, WYĆ) 'to wash', 'to howl'. }
\end{aligned}
$$

(KADRA, MODRA) 'staff', 'bright-blue (f.)',

(KARA, MORA) 'punishment', 'mora',

(KAWA, MOWA ) 'coffee', 'speech',

(KAC, MOC) 'hangover', 'power',

(KANTOWAĆ, MONTOWAĆ) 'to swindle', 'to assemble',

(KARALNY, MORALNY) 'punishable', 'moral',

(KANADA, MONADA) 'Canada', 'monad',

(KASTY, MOSTY) 'caste (pl.)', 'bridge (pl.)'.

(BARK, BRAK) 'shoulder', 'lack',

(BARĆ, $\left.B R A C^{\prime}\right)$ 'beehive in a hole in a log or tree', 'to take',

(DARN', DRAN') 'sod', 'scoundrel',

(KARTA, KRATA) 'card', 'bars',

(PARNY, PRANY) 'muggy', 'washed',

(BARWA, BRAWA) 'color', 'applause',

(GARB, GRAB) 'hump', 'hornbeam',

$(K A R B, K R A B)$ 'notch', 'crab'.

Comparing the isophonic paradigm with the diaphonic paradigm, fundamental differences can be discerned between them. The first is a set of phonotactemes, in which the same isodistributional isophonotacteme as well as different diaphonotactemes occur (see Bańczerowski 2013: 137f). The diaphonic paradigm, however, is a set of diacritic pairs of which each incorporates the same isodistributional diaphonic pair with respect to which the paradigm is isodiaphonic. In paradigm (8.1) this diaphonic pair is $(M-, W-$-), in paradigm (8.2) it is $(K A-, M O-)$, and in paradigm (8.3) it is $(-A R-,-R A-)$. Consequently, each diacritic pair which is an element of the diaphonic paradigm has in its composition a diaphonic pair, common to all the diacritic pairs of the paradigm, as well as an isophonotacteme, common only to those phonotactemes that form the pair. Thus, for example, the diacritic pair ( $K A W A$, 
$M O W A$ ) which is an element of paradigm (8.2) has the diaphonic pair (KA-, $M O-)$ common to all the pairs of that paradigm, as well as the isophonotacteme - $W A$ common only to the members of that diacritic pair.

Speaking somewhat metaphorically, in the phonotactic coding of the words of any language, two threads of phono-equalization may be recognized:

(i) equi-isophonic, and

(ii) equi-diaphonic.

These paradigmatizing threads wind through the universe of phonotactemes. The reciprocal action of these threads forms the corresponding phonotactic relations and objects, and among them phonotactic paradigms, which as indicated are based simultaneously on isophony and diaphony. Isophonotactemes and diaphonotactemes are then inalienable components of the phonotactic code. They themselves are, in turn, coded by means of phones or syllables.

The paradigm specified by a given diaphonic pair is a particular case of the dispersion of that pair in diacritic pairs. Moreover, each such paradigm is made up of two isophonic paradigms. A certain diaphonic analogy, or proportional diaphonic opposition, may be observed between any two diacritic pairs which are elements of the same diaphonic paradigm. It can then be said that the relation of diaphonic analogy binds, for example, the following diacritic pairs: (MATA, WATA), and (MODA,WODA), as well as $(B A R K, B R A K)$ and (DARN', DRAŃ), and others (cf. Bogusławski 1993).

The diaphonic paradigms specified by various diaphonic pairs may be sets with different numbers of elements, or they may differ with respect to their power. It appears that the dependence between these two objects can be captured by an empirical hypothesis which may be formulated as follows:

Hy 8.1 Diaphonic pairs made up of shorter diaphonotactemes specify paradigms of greater power than diaphonic pairs made up of longer diaphonotactemes.

The dynamic aspect of the operation specifying paradigms by diaphonic pairs can be grasped in terms of potency (energy) or force appropriately adjusted to the phonotactic reality. The paradigmaticizing potential of a given diaphonic pair could be called the product of the power of the paradigm specified by this pair and the probability of the occurrence of phonotactemes which form diacritic pairs being elements of that paradigm (cf. Bańczerowski 1987).

\section{Diaphonic coding}

The goal of diaphonic coding is to obtain the set of all diaphonotactemes and other diaphonic objects, in particular the set of all phonotactemes, for a given language. This is therefore a kind of passing from phones to linear structures made up of phones. Defining, as generally as possible, the diaphonic code sensu stricto, it can be said that it is created by a system of principles (and directives) governing the operation of diaphonotactemization, which associates diatactophonemes with the corresponding sets of target diaphonotactemes. Thus diaphonic objects of one kind are transformed into diaphonic objects of another kind. It should however be assumed that diaphonotactemization is based on the prior operation of 
diatactophonemization, which converts certain subsets of phones into diaphonic objects, in this case, diatactophonemes.

Consequently, within the framework of diaphonic coding, the following two operations are required:

(i) diatactophonemization, and

(ii) diaphonotactemization.

As concerns the first, it should be noted that not all subsets of phones will be susceptible to it, that is, only certain such subsets will function as diatactophonemes. With respect to this susceptibility, within the set of all subsets of phones the following two families may be distinguished:

(i) the family of diatactophonemes, and

(ii) the family of antidiatactophonemes.

It can be said that an antidiatactophoneme is an object which is empty diaphonotactemically, or in other words, is non-diaphonotactemizable.

The description of diaphonic coding is a rather complicated undertaking and demands the use of such entities as:

(i) the set of phones of a given language, as a point of departure,

(ii) the set of all subsets of those phones,

(iii) the set of articulatory categories of phones,

(iv) the set of diacritic pairs,

(v) the set of diatactophonemes,

(vi) the set of diaphonotactemes,

(vii) the operation of diatactophonemization,

(viii) the operation of diaphonotactemization.

All of the above objects and relations have been characterized above. However, neither the principles of diatactophonemization nor those of diaphonotactemization have been strictly defined by appropriate postulates. In the present approach we have been content merely with the empirical identification of diaphonotactemes within diacritic pairs. Subsequently diactactophonemes were obtained from diaphonotactemes. In formulating the grammar of the diaphonic code, work should proceed conversely based on the principles mentioned. The minimal (atomic) units of the diaphonic code are phones, which combine into diatactophonemes, and these in turn are linearized into diaphonotactemes.

\section{Final remarks}

The propositions presented above concern solely a certain rather regular fragment of the diaphonic aspect of phonotactics. Despite the abbreviated nature of the current description, a number of terms have been introduced, which should be useful for a comprehensive understanding of phonotactic reality from a diaphonic overview. The diaphonic code is only a sub-code of the phonotactic code, in which the isophonic sub-code also operates. Diaphony functions within the system of diacrisis, being operated to a considerable extent by phonotactics which, in turn, is strictly connected with other subsystems of language. Thus, in formulating a theory of the phonotactic system, it should be remembered that it is only relatively independent, since it functions within the language as a subsystem of certain 
suprasystems. In describing this system separately from the language as a whole, it is not possible to grasp a number of its essential characteristics, but an exhaustive description of this whole is, for obvious reasons, hardly feasible.

Signs as lingual objects are coded simultaneously with all the kinds of their constituent units which are certain wholes, that is, sounds, syllables, morphs, words. Each of these kinds of coding can be reflected upon with the appropriate representations which are already linguistic objects, in particular phonotactological ones, syllabotactological ones and so on.

Diaphonotactemes emerge as maximal units of the diaphonic coding of diacritic pairs. The threads of diaphony stretch through all words in every language, which in particular is reflected in the diaphonic load, diaphonic dispersion and the diaphonic paradigm. A quantitative picture of the spread of diaphony in a language could be obtained through appropriate calculations.

The phonotactic coding of lingual signs is one of the strategies of semantics and, speaking very generally, one of the strategies of lingual communication, for whose effective functioning the assurance of equalization and differentiation of these signs is indispensible. Phonotactics thus utilizes the isophonic and diaphonic sub-codes. It should not be forgotten, however, that one postulate states:

Po 10.1 No lingual sign is completely diaphonic with all other signs of a given language. The consequences of this postulate are rather obvious. They indicate a certain equilibrium between isophony and diaphony. Diaphonic extremism would be communicatively uneconomic.

Recognizing the principles of phonotactic coding in different languages may serve to establish phonotactic types of languages and in consequence a phonotactological typology within the framework of comparative phonotactology, which examines languages in terms of similarities and differences in the phonotactic coding of lingual signs. Such research, of course, would inevitably lead in the direction of the construction of a general phonotactology, as opposed to a particular one being in fact a phonotactological grammar of a given language.

\section{References}

Bańczerowski, Jerzy. 1987. Towards a dynamic approach to phonological space. Studia Phonetica Posnaniensia 1. 5-30.

Bańczerowski, Jerzy. 2009. Aspects of Chinese phonotactics against a comparative background of Polish. Scripta Neophilologica Posnaniensia 10. 7-22.

Bańczerowski, Jerzy. 2013. Izofoniczny aspekt fonotaktyki. In Migdał, Jolanta \& Piotrowska-Wojaczyk, Agnieszka (eds.), Cum reverentia, gratia, amicitia ... Księga jubileuszowa dedykowana profesorowi Bogdanowi Walczakowi, 127-139. Poznań: Wydawnictwo Rys.

Bańczerowski, Jerzy \& Pogonowski, Jerzy \& Zgółka, Tadeusz. 1982. Wstęp do językoznawstwa. Poznań: Wydawnictwo Naukowe Uniwersytetu im. Adama Mickiewicza.

Batóg, Tadeusz. 1967. The axiomatic method in phonology. London: Routledge \& Kegan Paul.

Batóg, Tadeusz. 1978. On the classical concept of phonemic basis. Lingua Posnaniensis 21. 53-64.

Bogusławski, Andrzej. 1988. Język i świat znaków (Language and the world of signs). Przeglad Humanistyczny 12. $133-168$. 
Bogusławski, Andrzej. 1993. O proporcjonalności w języku i jej warunkach. In Sambor, Jadwiga \& LindeUsiekniewicz, Jadwiga \& Huszcza, Romuald (eds.), Językoznawstwo synchroniczne i diachroniczne, 59-76. Warszawa: Wydawnictwa Uniwersytetu Warszawskiego.

Grucza, Franciszek. 1970. Sprachliche Diakrise im Bereich der Ausdrucksebene des Deutschen. Poznań: Poznańskie Towarzystwo Przyjaciół Nauk.

Wierzchon, Piotr. 2004. Gramatyka diakrytologiczna. Studium ortograficzno-kwantytatywne. Poznań: Wydawnictwo Naukowe UAM.

Zabrocki, Ludwik. 1962. Phon, Phonem und distinktives Morphem. Biuletyn Fonograficzny 5. 59-87.

Zabrocki, Ludwik. 1967. Phonologie und distinktive Morphologie. Actes du Xe Congrès International des Linguistes, 367-375. Bucharest. 